\title{
Aircraft Configuration and Flight Crew Compliance with Procedures While Conducting Flight deck based Interval Management (FIM) Operations
}

\author{
Rick Shay ${ }^{1}$, Kurt Swieringa ${ }^{2}$, and Brian Baxley ${ }^{3}$ \\ NASA Langley Research Center, Hampton, VA, 23681
}

\begin{abstract}
Flight deck based Interval Management (FIM) applications using ADS-B are being developed to improve both the safety and capacity of the National Airspace System (NAS). FIM is expected to improve the safety and efficiency of the NAS by giving pilots the technology and procedures to precisely achieve an interval behind the preceding aircraft by a specific point. Concurrently but independently, Optimized Profile Descents (OPD) are being developed to help reduce fuel consumption and noise, however, the range of speeds available when flying an OPD results in a decrease in the delivery precision of aircraft to the runway. This requires the addition of a spacing buffer between aircraft, reducing system throughput. FIM addresses this problem by providing pilots with speed guidance to achieve a precise interval behind another aircraft, even while flying optimized descents. The Interval Management with Spacing to Parallel Dependent Runways (IMSPiDR) human-in-the-loop experiment employed 24 commercial pilots to explore the use of FIM equipment to conduct spacing operations behind two aircraft arriving to parallel runways, while flying an OPD during high-density operations. This paper describes the impact of variations in pilot operations; in particular configuring the aircraft, their compliance with FIM operating procedures, and their response to changes of the FIM speed. An example of the displayed FIM speeds used incorrectly by a pilot is also discussed. Finally, this paper examines the relationship between achieving airline operational goals for individual aircraft and the need for ATC to deliver aircraft to the runway with greater precision. The results show that aircraft can fly an OPD and conduct FIM operations to dependent parallel runways, enabling operational goals to be achieved efficiently while maintaining system throughput.
\end{abstract}

\section{Nomenclature}

$\begin{array}{ll}\text { ADS-B } & =\text { Automatic Dependent Surveillance-Broadcast } \\ \text { ASG } & \text { Assigned Spacing Goal } \\ \text { ASTAR10 } & \text { Airborne Spacing for Terminal Area Routes (Version 10) } \\ \text { ASTOR } & =\text { Aircraft Simulation for Traffic Operations Research } \\ \text { ATOL } & =\text { Air Traffic Operations Laboratory } \\ \text { ATOS } & =\text { Airspace and Traffic Operations simulation } \\ \text { CDA } & =\text { Continuous Descent Arrival } \\ \text { CDTI } & =\text { Cockpit Display of Traffic Information } \\ \text { CPDLC } & =\text { Controller-Pilot Datalink Communication } \\ \text { DTG } & =\text { Distance-To-Go } \\ \text { DTS } & =\text { Development and Test Simulator } \\ \text { EICAS } & =\text { Engine Indicating and Crew Alerting System }\end{array}$

${ }^{1}$ Aviation Consultant, President, Double Black Aviation Technology L.L.C., Littleton CO, AIAA Senior Member.

${ }^{2}$ Research Engineer, Crew Systems and Aviation Operations Branch, NASA LaRC, MS 152, SS.

${ }^{3}$ Research Engineer, Crew Systems and Aviation Operations Branch, NASA LaRC, AIAA Senior Member. 


$\begin{array}{ll}\text { FAS } & =\text { Final Approach Speed } \\ \text { FIM } & =\text { Flight deck based Interval Management } \\ \text { FMC } & =\text { Flight Management System } \\ \text { FMS } & =\text { Ground based Interval Management } \\ \text { GIM } & =\text { Global Operational Data Link Document } \\ \text { GOLD } & =\text { Human-In-The-Loop } \\ \text { HITL } & =\text { Integration Flight Deck } \\ \text { IFD } & =\text { Interval Management with Spacing to Parallel Dependent Runways experiment } \\ \text { IMSPiDR } & \text { Dallas Love Field } \\ \text { KDAL } & =\text { Dallas Fort-Worth airport } \\ \text { KDFW } & =\text { Lateral Navigation } \\ \text { LNAV } & =\text { Multi Aircraft Control System } \\ \text { MACS } & =\text { Multi-Function Control Display Unit } \\ \text { MCDU } & =\text { Node Control Panel } \\ \text { MCP } & =\text { Optimized Profile Descent } \\ \text { ND } & =\text { Primary Flight Display } \\ \text { OPD } & =\text { Required Time of Arrival } \\ \text { PFD } & =\text { Radio Technical Commission for Aeronautics } \\ \text { RTA } & =\text { Random Update Cycle (13 kilometer resolution) } \\ \text { RTCA } & =\text { Top of Descent } \\ \text { RUC-13 } & =\text { Time-To-Go } \\ \text { TOD } & \text { TTG } \\ \text { VNAV } & =\end{array}$

\section{Introduction}

\section{A. The Development of Flight deck Interval Management}

The Federal Aviation Administration (FAA) forecasts commercial aviation will grow on average 3.7\% per year over the next twenty years, with the number of revenue passenger miles to double by 2031. ${ }^{1}$ As one method of accommodating this expected growth and improving the safety of operations, NASA and the FAA are collaboratively developing a concept of operations called Flight deck based Interval Management (FIM). ${ }^{2,3}$ The development of FIM technologies is an international effort that will enable any Air Navigation Service Provider (ANSP) to assign FIM equipped aircraft a precise interval that can be achieved behind another aircraft. FIM is a suite of functional capabilities that can be combined to improve both the safety and efficiency of flight operations.

During FIM operations, the Air Traffic Controller (ATC) retains the responsibility for maintaining safe separation between aircraft. ATC uses Ground based Interval Management (GIM) equipment to determine an arrival schedule that includes the spacing interval pilots need to achieve, permitting ATC to assign the spacing clearance to properly equipped aircraft. Pilots will then use FIM equipment to achieve the interval assigned by ATC. FIM operations utilize the Global Positioning System (GPS) data, Automatic Dependent Surveillance - Broadcast (ADSB) data, onboard navigational data, and algorithms to achieve the spacing between aircraft. The FIM equipment uses this data to provide the proper guidance for speed deviations from the nominal profile, allowing the aircraft to achieve its ATC assigned spacing interval. The spacing task described in this paper is based on using speed control to achieve the desired interval behind preceding aircraft arriving to dependent parallel runways.

In addition to improving safety and the landing rate at congested airports, it is important for airlines to improve the efficiency of their operations, even when maximizing throughput is not critical. To help improve efficiency, it is desired that every flight performs an Optimized Profile Descent (OPD) to reduce fuel consumption, noise, and emissions. The ideal speed for an OPD can vary considerably based on the aircraft type, aircraft weight, and wind. Furthermore, the airline may wish to modify this speed to improve schedule reliability or to improve fuel efficiency. FIM is designed to have the aircraft operate with small deviations from their OPD, while meeting the schedule required for high-density operations. This paper examines the competing interests between reducing fuel consumption, achieving airline operational goals for individual aircraft, and the need for ATC to deliver aircraft to the runway with greater precision.

2

American Institute of Aeronautics and Astronautics 


\section{B. FIM Research on Dependent Parallel Runway Operations}

Previous NASA research of FIM to independent runway operations has shown pilots are able to conduct these FIM operations, and arrive at the runway threshold within 5 seconds of the ATC assigned spacing interval. ${ }^{4}$ Ongoing work by the FAA has led to a safety analysis, a description of procedures, and a description of requirements for FIM operations in a complex terminal environment to a single runway. ${ }^{5}$ More recently, the FIM concept has been expanded to accommodate parallel dependent runway operations, ${ }^{6}$ and a new version of the Airborne Spacing for Terminal Arrival Routes (ASTAR) algorithm created to meet the unique requirements for these operations (ASTAR10). ${ }^{7}$ A Human-In-The-Loop (HITL) experiment called Interval Management with Spacing for Parallel Dependent Runways (IMSPiDR) was conducted at NASA Langley Research Center in the summer of 2011. This experiment explored the concept, and indicated, within certain constraints and conditions, that pilots are able to conduct FIM operations. ${ }^{8,9,10}$ In addition to the additional aircraft spacing requirements for dependent parallel runway operations, the IMSPiDR experiment employed OPDs to determine if aircraft operators could use small speed deviations from the optimal profile to correct spacing errors, allowing the use of OPDs in a high density environment.

Dependent runway operations have specific separation requirements for aircraft operating on approaches to parallel runways. These requirements are based on the distance between the parallel runways. For runways laterally separated by more than 4,300 feet, a minimum separation of $2 \mathrm{NM}$ distance must be maintained between aircraft on parallel approaches (Figure 1). The minimum separation between aircraft arriving to the same runway (the in-trail wake separation) depends on the weight class of both aircraft.

Operational efficiency is a multi-faceted problem. Although fuel is a major cost factor for airlines, the cost of equipment, the cost of labor, and the need to ensure passengers and cargo can make their connections also factor into

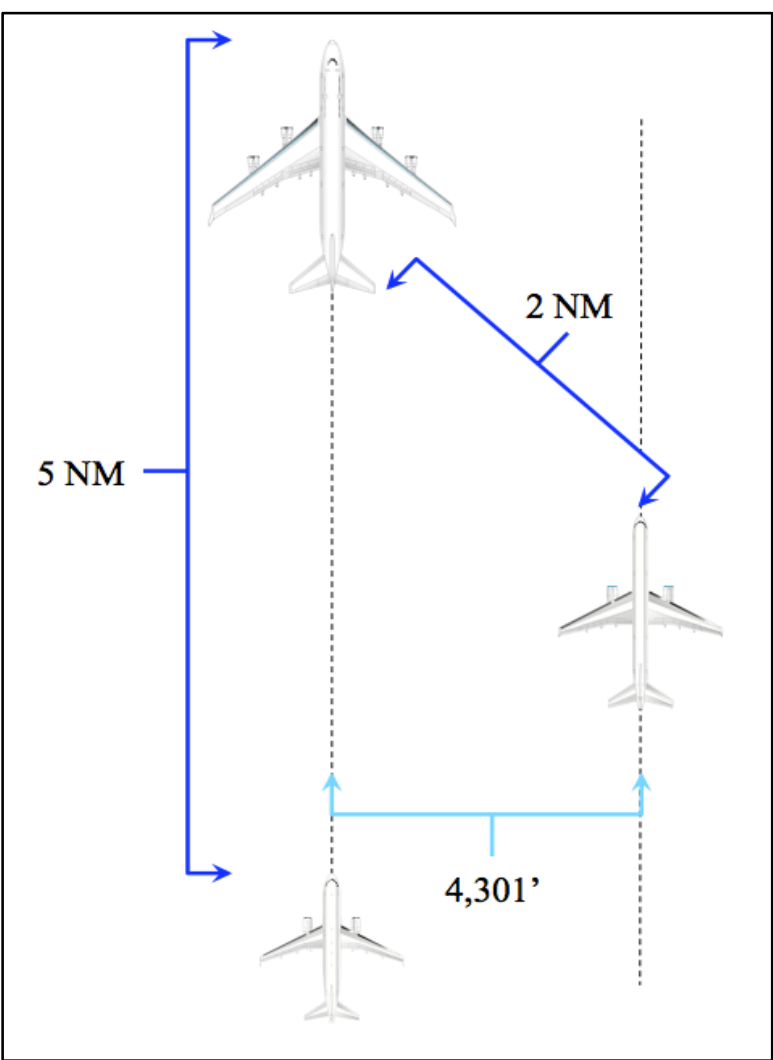

Figure 1. Separation Criteria. the efficiency of operations. As a result, achieving high operational rates and improving efficiency while maintaining or improving safety is important for airlines. During operations today, an OPD allows the flight crew the flexibility to efficiently achieve their operational goals, up until a speed instruction is issued by ATC. When FIM capabilities are added to an OPD operation, the pilots have the ability to fly their original OPD profile until it is necessary to adjust their speed to meet the ATC assigned spacing interval with aircraft landing ahead of them. One of the design goals of FIM is to have the cost of these speed changes generated onboard the aircraft to be smaller than the cost of complying with ATC issued speed instructions. This is achieved by making small speed deviations from the nominal profile over the course of the arrival, decreasing the need for vectoring and large speed deviations to achieve the ATC assigned spacing interval.

This paper describes some of the characteristic behaviors of FIM operations, and the impact on this operation caused by how the pilots configured their aircraft, and by how well the pilot conforms to the FIM procedures. Both quantitative and qualitative data was collected from the experiment, including aircraft state data, FIM performance data, questionnaires, and data from verbal debriefs. Qualitative results pertaining to the flight crew's compliance with the training they received, the timeliness of their responses to speed changes, and other issues raised by the subject pilots are also discussed. 


\section{Experiment Method}

\section{A. Experiment Background}

The IMSPiDR experiment was created to investigate the FIM control algorithm to support dependent parallel runway operations during high density throughput conditions, and the pilot procedures to conduct them in the presence of different sources of error. Objectives of this experiment included delivering aircraft to the runway threshold with precision, ensuring the stability of aircraft arrival streams, ensuring pilot workload remained acceptable, and identifying potential operational issues of the FIM concept. Scenarios and parameters were selected to test the spacing algorithm and pilot procedures under stressful conditions (steep high-energy OPDs, complex CPDLC messages, a non-ideal CPDLC interface, high traffic volume, large perturbations, etc.). Some of these conditions and interfaces may not be representative of an ideal implementation of FIM.

The operational goal of FIM during this experiment was the precise delivery of aircraft at the runway threshold behind the preceding (Target) aircraft. This experiment used 24 current commercial pilots to fly OPD arrivals into the Dallas Fort-Worth (KDFW) airport. Pilots were asked to follow onboard guidance to precisely space their aircraft behind a preceding aircraft in one of three different types of simulators at the NASA Langley Research Center. Each simulator type contained slightly different hardware and interfaces, enabling the evaluation of different aircraft equipage levels and different pilot procedures.

\section{B. Experiment Description}

A schedule of arrival times for all aircraft arriving into KDFW was assumed for each scenario, and it established the arrival sequence and spacing interval between each pair of aircraft at the runway threshold. Either a Required Time of Arrival (RTA) or an RTA and FIM (RTA+FIM) clearance was issued by ATC to the pilots after the start of each scenario and prior to Top Of Descent (TOD). Controller-Pilot Data Link Communication (CPDLC) was used to issue and respond to these clearances. After receiving the clearance via CPDLC, the pilots followed current operational Data Communication procedures to 'auto-load' the clearance into the FIM spacing tool, evaluate the calculated FIM speed, and then accept or reject the clearances via CPDLC. After sending the CPDLC accept message, the pilots were required to execute the FIM operation, causing FIM guidance to appear on the aircraft's displays. If the aircraft had received a RTA+FIM clearance and was out of ADS-B range from its lead aircraft, the FIM avionics provided pilots with speeds to achieve an RTA at the runway. Once the Target aircraft was within ADS-B range, ASTAR transitioned from achieving a precise time at the runway (RTA mode) to achieving a precise interval behind the Target aircraft (FIM mode).

Since the aircraft in this experiment had two Target aircraft, the FIM speed was calculated by the ASTAR10 algorithm to meet or exceed the Assigned Spacing Goal (ASG) for both Target aircraft. The ASG can be specified as a time or distance, and is the interval behind the Target aircraft that is to be achieved relative to the runway threshold. For IMSPiDR, time (in seconds) was used as an additional measure of clarity for the pilots when spacing behind a Target aircraft to the same runway; distance (in nautical miles) was used when spacing behind a Target to the parallel runway. When valid ADS-B position data for both aircraft is available, the error to achieve both spacing intervals is calculated, but the FIM speed displayed to the crew is based on the 'controlling aircraft'. The 'controlling aircraft' is the Target that places the FIM aircraft farthest aft, thereby ensuring both ASGs are met or exceeded.

\section{Operational Environment}

Fourteen different arrivals were developed into KDFW by laterally overlaying existing arrival routes and removing most altitude constraints (approach constraints were retained) and creating the steepest angle considered acceptable by the FAA's Terminal Area Route Generation, Evaluation, and Traffic Simulation (TARGETS) software. These arrivals were designed to emulate OPDs that connected to an instrument approach to Runway 17 Center or 18 Right (south flow operations at KDFW). Subject pilots flew the Masty, Bonham, or Cedar Creek charted OPDs to the ILS to Runway 17 Center while following FIM speed guidance. Pilots optimized the charted profile by allowing the FMS to determine the proper top of descent for the aircraft weight and actual winds.

Each scenario contained 35 aircraft arriving into KDFW, with an additional 25 aircraft departing KDFW and 4 aircraft arriving to Dallas Love Field (KDAL). The initial position, callsign, route, altitude, and arrival sequence for all 64 aircraft were identical during the ten data collection runs, with the six aircraft flown by subject pilots initialized in the middle of the arrival stream (shown as magenta arrows in Figure 2).

4

American Institute of Aeronautics and Astronautics 


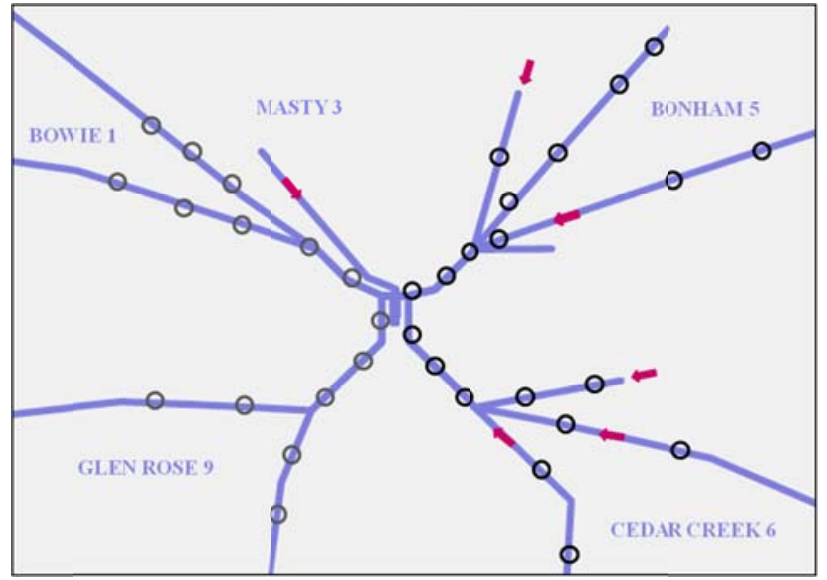

l Position.
Each scenario initialized the subject pilots at one of the positions shown as a magenta arrow. For ease of identification, the six aircraft flown by subject pilots used a NASA callsign. Arriving aircraft not flown by subject pilots were operated using automated ASTOR stations (aircraft on the Glen Rose landing on Runway 18R, aircraft on the Bowie landing Runway 18R, and aircraft on the Bowie landing at KDAL). Aircraft departing KDFW were generated by the MACS simulation software, and the standard departure routes were modified slightly to provide visual traffic to the pilots in the full-scale simulators.

\section{Experiment Apparatus}

\section{Simulators}

IMSPiDR used three different simulation platforms to explore different FIM equipment configurations, and different FIM pilot procedures. All of the simulation platforms had comparable flight deck components including: aircraft and engine models, autopilot and auto-throttle systems, Flight Management System (FMS), Multifunction Control Display Unit (MCDU), Mode Control Panel (MCP), Electronic Flight Instrumentation System (EFIS), PFD, ND, Engine Indication and Crew Alerting System display (EICAS), CPDLC, and the standard communications. Additionally, each simulation platform contained advanced technology components, including Cockpit Display of Traffic Information (CDTI), and FIM controls and indications.
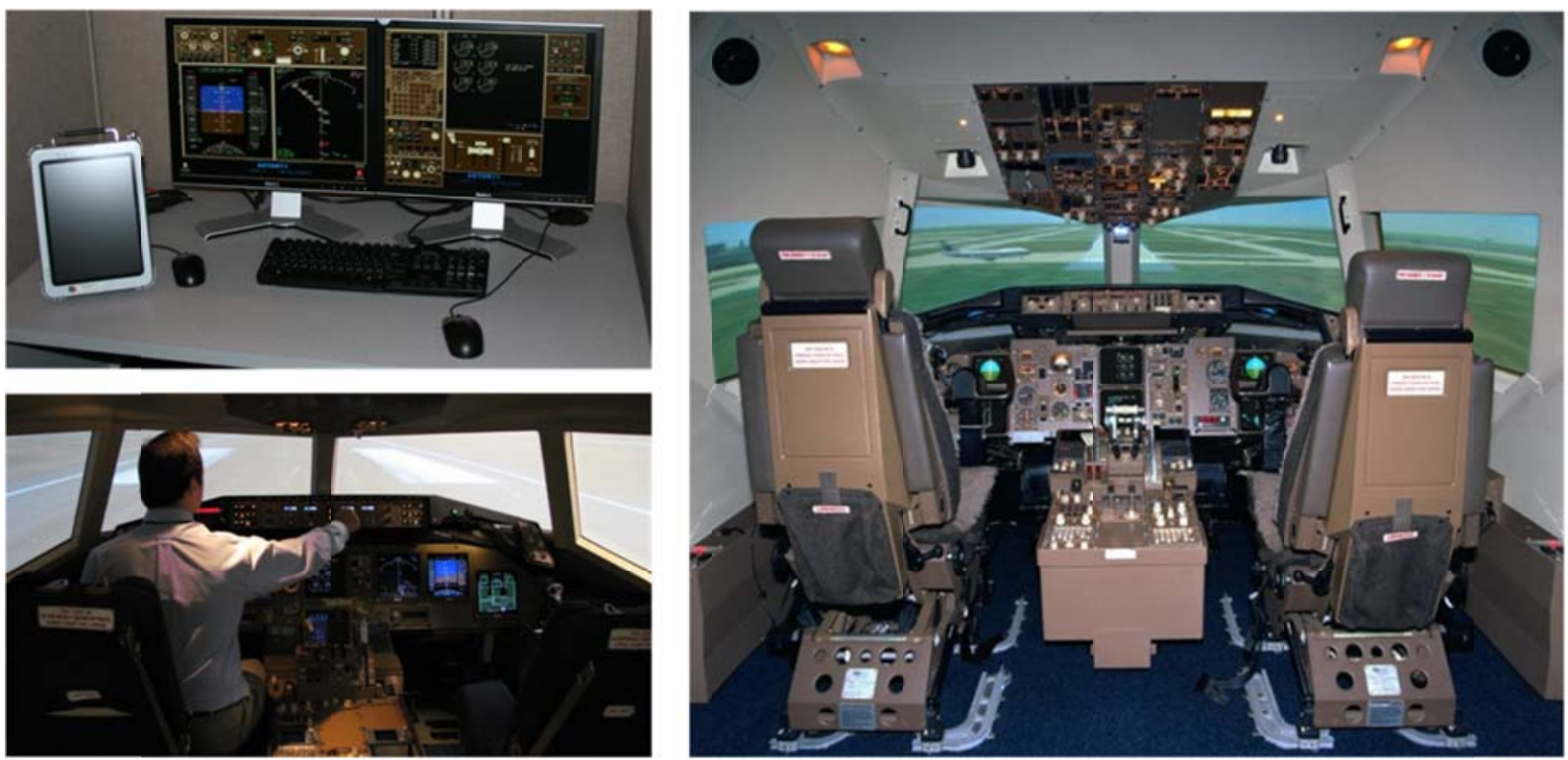

Figure 3. Clockwise from the bottom left: (a) Development and Test Simulator (DTS), (b) Aircraft Simulation for Traffic Operations Research (ASTOR) (c) Integration Flight Deck (IFD).

The first simulator used in the IMSPiDR experiment was the Development and Test Simulator (DTS). The DTS is a full-scale simulator representative of a large commercial transport category aircraft (Figure 3a). The DTS requires two pilots to operate and has a $210^{\circ}$ horizontal by $45^{\circ}$ vertical out the window field of view. It is equipped with eight D-Sized displays, sidestick controls, rudder pedals, two color Control Display Units (CDU), and 


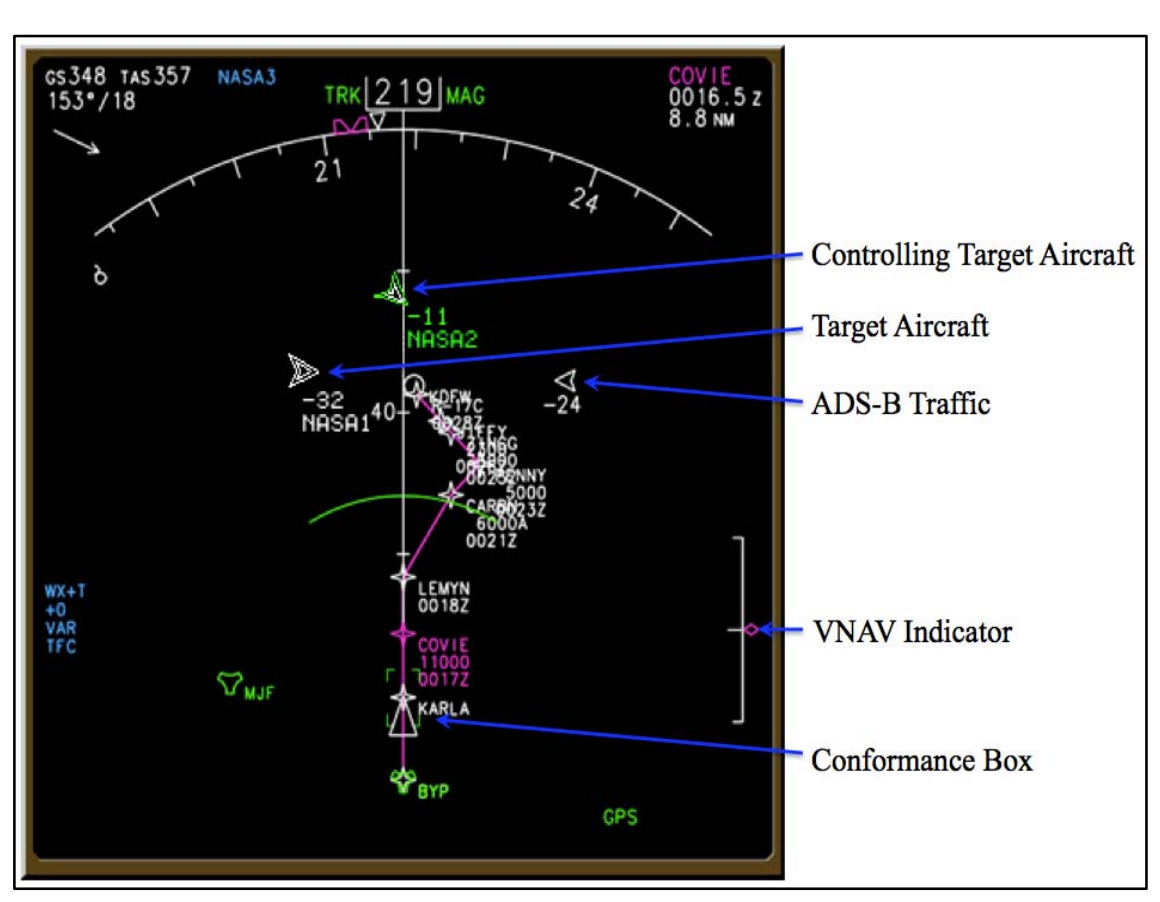

Figure 4. ASTOR Navigation Display.

additional interface devices derived from a variety of other transport aircraft. The visual display was the KDFW terminal environment and all aircraft traffic in a daytime setting.

The second simulation platform was located within the Air Traffic Operations Laboratory (ATOL) which employs the Airspace and Traffic Operations Simulation (ATOS) platform and the Multi Aircraft Control System (MACS). ATOS is a network of Aircraft Simulation for Traffic Operations Research (ASTOR) computer stations with two video monitors, equipped with experimental cockpit displays and pilot interfaces operated by a single pilot or software logic known as 'Pilot Model' (Figure 3b). Components include: a six degrees of freedom equations of motion aircraft model, PFD, ND, autopilot, auto-throttle, FMS, MCDU, MCP, CPDLC, ADS-B, and ASTAR10.

The third simulator used in the IMSPiDR experiment was the Integration Flight Deck (IFD). The IFD is a fullscale, high-fidelity simulator of a large commercial transport aircraft with standard operational instruments (Figure 3c). The cockpit's visual system is a panorama system that provides $200^{\circ}$ horizontal by $40^{\circ}$ vertical field-of-view. The IFD visual scene is identical with the DTS.

\section{FIM Displays on PFD and ND}

For this experiment, FIM displays were integrated with normal aircraft displays. FIM speed guidance was placed on the PFD, depictions of the Target aircraft on the ND, three new pages were added to the MCDU, and ASTAR memos and cautions were displayed on the EICAS display.

The FIM displays on the PFD included the commanded end speed, a commanded speed bug, and ASTAR modes (Figure 5). The FIM commanded end speed is depicted by green numbers above the speed tape. The pilots were instructed to set this speed in the MCP speed window when the aircraft was in VNAV SPEED mode. Whenever a speed change occurred, the commanded end speed was outlined by a green box for ten seconds to help pilots notice the change. In addition to the commanded end speed, a FIM speed bug was added to the speed tape. The speed bug depicted the FIM commanded end speed adjusted for ASTAR10's estimation of the aircraft's deceleration rate, and was intended to provide the crew with a precise indication of the desired speed at any given moment. The FIM speed bug was displayed as a green bowtie (ASTOR), triangle (DTS) or line (IFD) just to the right of the speed tape. Subject pilots were instructed to configure the flaps on their aircraft as they would in normal operations and use speed brake and throttles as necessary to remain within \pm 5 knots of FIM commanded speed (the green speed bug or line). The speed bug on the speed tape of the PFD was sized to help the pilots meet this 5 knot limit (discussed in Pilot Training section).

In addition to the commanded end speed and FIM speed bug, an ASTAR mode indicator was located next to the commanded end speed. The mode indicator shown to the right of the FIM speed on the PFD was intended to tell the pilot what mode the ASTAR10 algorithm was using to calculate the FIM commanded speed. When the ASTAR mode changed, a green box appeared around the ASTAR mode indicator for ten seconds (shown as IM in the left and right panel of Figure 5, and as FNL (final approach speed) in the center panel). 

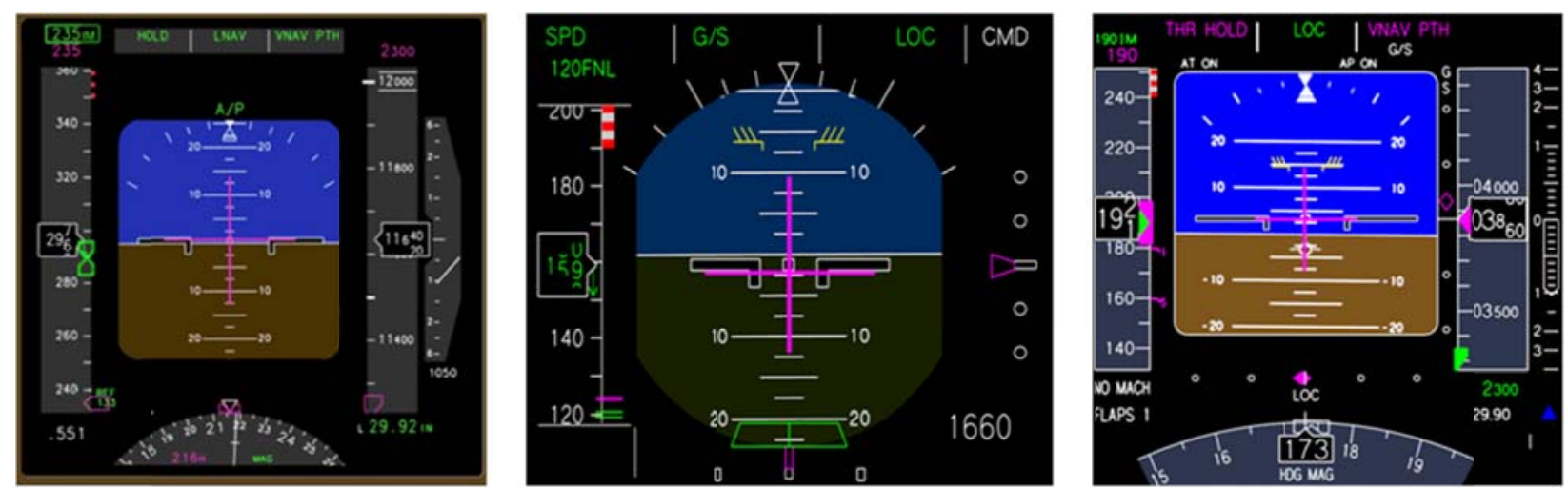

Figure 5. From left to right, (a) ASTOR PFD, (b) IFD PFD, (c) DTS PFD.

The ND on all three simulators presented essentially the same information, with the DTS and IFD using diamonds as the traffic symbol, and the ASTOR as a chevron (Figure 4). The ND enabled pilots to monitor the relative position of proximate traffic, and identify the controlling Target aircraft, and the second Target aircraft. The VNAV vertical deviation indicator also provides feedback on how the aircraft is conforming to the optimized vertical profile. Additional information provided on the ND included: "own-ship" callsign, Target aircraft callsigns, ADS-B Traffic, and the Lateral Navigation (LNAV) route. During the one exploratory scenario, a FIM conformance box was also added to the ND, allowing pilots to quickly determine how well the spacing operation was proceeding.

Three new pages were added to the MCDU to support the FIM operation. The first page contained information about the spacing operations such as the ASTAR mode, achieve-by point, the callsigns of the lead aircraft, the final approach speeds of the lead aircraft, and the spacing errors. The spacing error for the aircraft arriving to the same runway was shown as a time error and the spacing error for the aircraft arriving to the parallel runway was depicted as a distance error. The second and third FIM MCDU pages contained additional information about each lead aircraft, such as their FIM goal, achieve-by point, and route.

The EICAS display provided advisories, warnings, and cautions to the flight crew. Cautions indicated ASTAR faults such as a loss of ADS-B data, a lead aircraft off path, or that the time error was excessive. Advisories could indicate that the spacing aircrafts' path had errors, the spacing aircraft was off path, or if the Target aircraft had bad path information. The memos were designed to provide the pilots with increased awareness of the FIM operation, and help them stay on track if they deviated too far from the commanded speed. Some of the memos included a drag required message, a message notifying the pilot that the algorithm was constraining the commanded speed, and a message that notified the pilots that they had acquired the ADS-B signal from their lead aircraft and had transitioned form RTA to FIM mode.

\section{FIM Clearances and EICAS Display}

Prior to reaching Top Of Descent (TOD), flight crews received either an RTA or RTA+FIM clearance from ATC. Due to the complexity of an RTA+FIM clearance for dependent parallel runway operations, CPDLC was used to transmit the FIM clearances. The content of the clearance used existing guidance from the standards development work by the Radio Technical Commission for Aeronautics (RTCA) SC-214/EUROCAE WG-78 - FAA working group, and the Global Operational Data Link Document (GOLD). ${ }^{11,12}$

A complete RTA+FIM clearance contained: the assigned runway, the RTA at the runway, a conditional instruction to transition to interval spacing when able, the Target aircraft callsign, the ASG behind that Target, the Target's route of flight, and the Target's Final Approach Speed (FAS). All the necessary information for a second Target was included if appropriate, as well as an instruction to report to ATC when the FIM operation had begun. In contrast, the RTA clearance simply contained the runway and an arrival time. An example of a CPDLC message containing a RTA+FIM clearance is shown below.

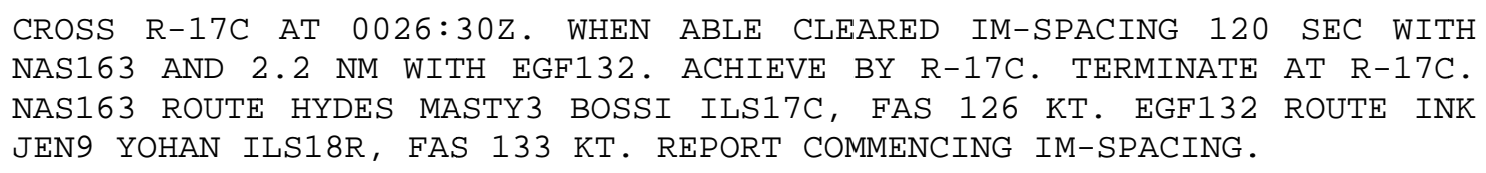


The corresponding RTA only clearance is:

CROSS R-17C AT $0026: 30 Z$.

Additionally, the interfaces pilots used to interact with the RTA and RTA+FIM clearances depended on the type of simulator flown. Pilots flying ASTOR simulators used the EICAS display to access CPDLC messages (Figure 6), and pilots flying the IFD and DTS used the MCDU (not shown). CPDLC messages containing the FIM clearance were loaded directly into the FMS. All FIM functions and information were accessed through the MCDU.

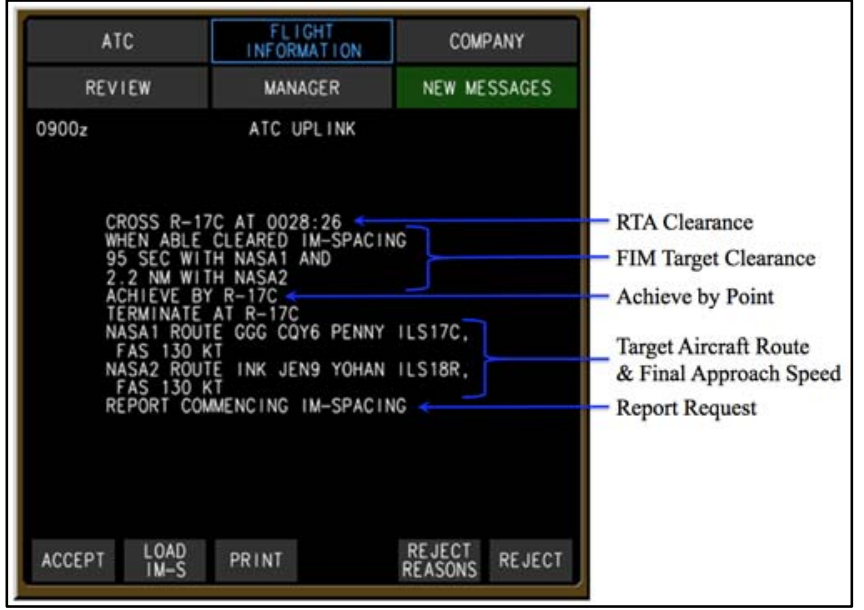

Figure 6. CPDCL Message Elements.

\section{E. Training and Pilot Procedures}

Each subject pilot received written CPDLC and FIM instructions using the ASTOR displays and indications. This was followed by individual instruction and hands-on training in the simulators. Pilots were advised that FIM commanded speeds provided guidance to achieve both a stabilized approach and the ATC desired interval, and that the aircraft may not be properly configured for the commanded speed. Pilots were instructed to extend or retract flaps as necessary to remain within the flap limit speeds and to configure their aircraft to achieve a stabilized approach. Pilots were also advised that FIM commanded speeds may require them to extend flaps and gear later during the arrival and approach than they were accustomed to. Pilots were not required to know which of the two Target aircraft the displayed FIM speeds were based on, nor were pilot actions required when the spacing algorithm switched from one Target aircraft to the other, or from RTA to FIM mode. Pilots could, however, ascertain which Target aircraft the IM speeds are based on by reviewing the FIM pages of the MCDU, or by observing double chevron in green on the ND (Figure 4).

During the hands-on training, pilots practiced receiving and reviewing the FIM clearance sent via CPDLC, loading the clearance into the FIM software, and then activating the FIM software. Activation of the FIM software caused the FIM speed to be calculated. The pilots were then asked to determine it the calculated FIM speed was acceptable or not. If the pilot determined that the FIM speed and clearance were feasible, the pilots accepted the FIM clearance over CPDLC, executed the FIM operation, and ensured that the aircraft's commanded speed was set to the FIM commanded speed. If the FIM clearance was not acceptable, the pilots rejected the FIM clearance using CPDLC.

Pilots were advised that OPD arrivals are operated at reduced drag configurations and carry high speeds closer to landings than many are accustomed to. As a result, the aircraft's high kinetic energy during descent required careful monitoring of airspeed, and timely configuration of the aircraft was essential to achieving a stabilized approach. Therefore, the guidance given to pilots for descent was to remain within 5 knots of the commanded FIM speed (green speed bug in Figure 5) using drag devices as necessary, and to remain within 600 feet of the vertical path to ensure all crossing restrictions were met. Pilots were also required to monitor the EICAS display for messages, one of which was triggered when the aircraft was too fast and required additional drag to achieve the FIM speed.

The guidance given to pilots for achieving a stabilized approach was to extend flaps prior to reaching the minimum flap maneuvering airspeed but no earlier than the placard-5 knots limit. When the FIM commanded speed transitioned to FNL mode, they were expected to lower the landing gear, extend the flaps to 20, set the aircraft target speed in the MCP window, and configure as necessary to be stable by 1000 feet AGL.

The pilot procedures were designed for the following events:

1. Scenario began at cruise altitude or on descent with autopilot and auto-throttles engaged.

2. The route, arrival, and ILS were programmed into Route 1 of the FMC.

3. The descent profile speeds of CRZ MACH/300 were programmed into the FMC descent page.

4. Forecast Descent winds were programmed into the FMC for FL400; 10,000; 5,000; and 600 feet MSL.

5. The MCP altitude window was set to 2300 feet.

6. Every flight had been cleared for their OPD arrival.

7. Both LNAV and VNAV PATH were active (ATOL and DTS only; IFD always VNAV SPEED). 
8. Pilots received, loaded, verified, accepted, and activated FIM message for Interval Management.

9. Pilots were expected to maintain their aircraft speed within \pm 5 knots IAS of commanded FIM speed.

10. Pilots were expected to arm the approach mode on their aircraft between 6-2 miles of Final Approach Fix.

11. Pilots manually set the FIM speed in the MCP window after glide slope intercept (ATOL and DTS only; the pilots in the IFD set the FIM speed in the MCP window throughout the scenario).

12. Pilots were expected to configure the aircraft and achieve a stabilized approach prior to 1,000 feet AGL.

\section{F. Pilot Participants}

A total of 24 current commercial airline pilots, employed by major U.S. air carriers, participated in this experiment. The pilots ranged in age from 37-61 years old, had an average of twenty years of flight experience, and over 11,000 hours of flight time. At the time of the study, seventeen of the participants served as Boeing 777 pilots; four served as 757/767 pilots; two served as 747 pilots; and one served as a 737 pilot. To minimize potential effects associated with different airline operating procedures, all two-person crews were paired from the same airline.

\section{G. Experiment Design}

This experiment used three groups of pilots who each flew six distinct scenarios, as well as one exploratory scenario (not discussed in this paper). The six scenarios were designed to investigate the impact of three error sources (no error, offset error, and wind error), and two different control methods (RTA only and RTA+IM). Two replicates of each scenario containing offset errors and wind errors were conducted, creating a total of ten nominal runs per group and one exploratory run.

Table 1. Experiment Design Matrix.

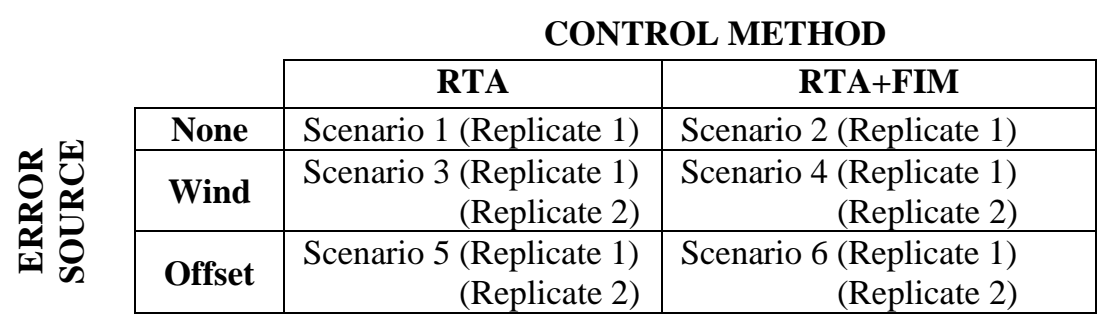

\section{Independent Variables}

The independent variables in IMSPiDR were the error source and control method. The values for the error source were no error (baseline), impulse perturbation (offset error), and a difference between forecast and actual winds (wind error). The values for the control method were time only (RTA, aircraft arrives at the runway threshold at a precise time), and time plus relative spacing (RTA+ FIM, aircraft initial controls to time, then transitions to achieving a precise interval behind the preceding aircraft).

The wind error included a difference in both magnitude and direction, and was derived using actual National Oceanic and Atmospheric Administration (NOAA) winds and the expected error of the 3 hour forecast for a Rapid Update Cycle weather model with 13 kilometer resolution (RUC-13). This RUC-13 error was multiplied by 1.5 to simulate an instance where the RUC-13 model is less accurate due to rapidly changing weather conditions, and a significant wind shear event was added at 5000' MSL where the merge onto final approach occurs. Thus, this wind error is one that pilots are rarely expected to experience.

The offset error was a disturbance injected into the system when the aircraft in front of the first piloted aircraft descended below 9,000ft, and was designed to simulate an instance where ATC had to modify the spacing interval of an aircraft to fit an additional aircraft into the flow. The offset error was implemented differently in the IM scenarios and the RTA scenarios. In the RTA+FIM scenarios, the aircraft in front of the first human piloted aircraft had its spacing interval increased by 30 seconds, and this increase was allowed to propagate backwards through the stream. Thus a CPDLC message was only required for the one aircraft. In the RTA scenarios, the aircraft in front of the first human piloted aircraft, and all of the aircraft arriving later than this aircraft had their arrival times moved 30 seconds earlier. Thus a CPDCL message had to be sent to each aircraft with the new RTA. 


\section{Dependent variables}

There was a variety of quantitative and qualitative data collected for this experiment. The qualitative data included a pre-experiment questionnaire designed to gather biographical data from the participants, a post-run questionnaire to gather workload ratings as well as ratings pertaining to the spacing operation, and an extensive post-experiment questionnaire designed to gather pilot feedback on the interfaces and procedures used in the experiment. Additionally, a verbal debrief was conducted after each group of pilots had completed the experiment, giving them an opportunity to voice their thoughts, opinions, and concerns about the FIM operation.

Quantitative data collected during this experiment included aircraft state data as well as data from the spacing algorithm. The quantitative data of interest for this experiment included the time error at the runway threshold, the number of speed changes, pilot conformance to speed changes, pilot reaction time to speed changes, and various other performance metrics such as flap deployment times and speedbrake usage. The data of particular interest in this paper includes the pilot reaction times to speed changes, flap deployment times, and gear deployment times.

\section{Exploratory Scenario}

The final scenario completed by each group of pilots was an exploratory scenario designed to examine various off-nominal events during which only subjective data was collected. The exploratory scenario had a number of differences from the nominal scenarios. First, the spacing interval was decreased from 120 seconds to 75 seconds to simulate an arrival flow with greater density. Secondly, a new display element, the 'conformance box,' was added to the ND to provide pilots the ability to determine how FIM operations were proceeding (Figure 4). Lastly, there were a number of events that were included in the exploratory scenario. The most notable event was a go-around that pilots of the IFD were required to conduct due to insufficient spacing. Events other simulators encountered included a clearance to space off an aircraft landing on runway 13R and an instance where a lead aircraft, who was originally on the same route, switched to a parallel runway. Pilots were briefed that this scenario was different than the rest, but were not told of specific circumstances that would occur during the scenario.

\section{H. ASTAR Spacing Algorithm}

The ASTAR10 algorithm, designed to support operations to dependent parallel runways, has performance and capabilities similar to previous versions used for operations to single runways. The maximum speed deviation ASTAR10 can command is $\pm 10 \%$ of the profile speed. This prevents ASTAR from commanding speeds that are unacceptably low or high for the FIM pilot, and produces more predictable and stable behavior for following aircraft and ATC. An estimate of the amount of time delay or gain the spacing algorithm can achieve for a generic arrival is shown in Figure 7. The aircraft's delay time (red line) is slightly greater than the time it can gain (blue line) due to the requirement to remain at 250 knots or less when at or below 10,000' MSL, and the

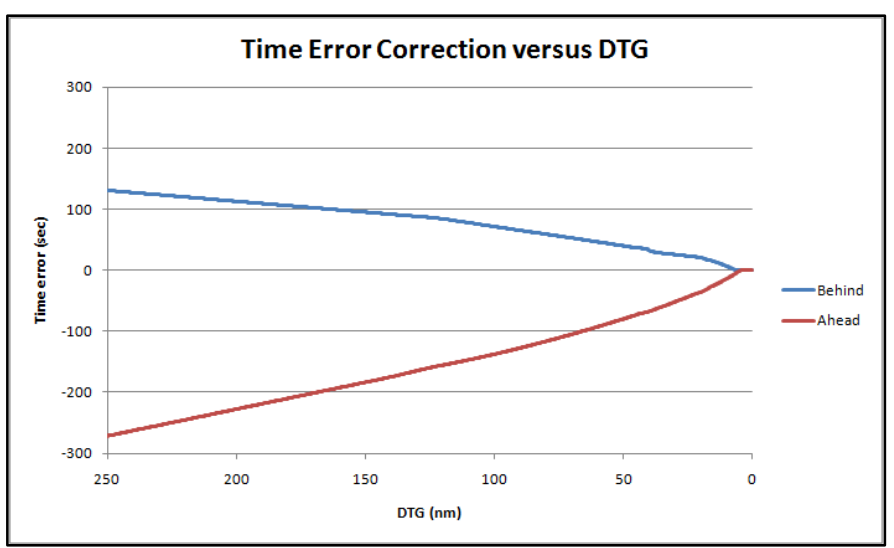

Figure 7. Correctable Time Error vs. Distance-To-Go. deceleration rate needed to achieve a stabilized approach by 1000' AGL.

To support dependent parallel runway operations, the ASTAR10 algorithm uses ADS-B state data from both Target aircraft: one arriving to the same runway, and one arriving to the parallel runway. The Target that required the greatest delay was used by ASTAR10 to calculate the FIM speed. ASTAR10 uses the 4D trajectories of the spacing aircraft and the lead aircraft to determine their TTG until they reach a designated "achieve-by" point.

The TTG values along with a designated spacing interval are used to determine a time error, which is filtered and multiplied by a gain to obtain the commanded speed. The filters and gain schedule in ASTAR were designed to help pilots achieve precise spacing intervals, while limiting the number of speed changes provided to pilots and ensuring operationally acceptable speeds. To limit the number of speed changes that pilots received when they were far from the runway, the gain was reduced, and a filter decreased the value of time error used to generate the IM commanded speed. 
The effect of the filtering and gain scheduling within ASTAR (Figure 8) creates small corrections for a given time error when the aircraft is far from the runway, and corrects more aggressively as the aircraft approaches the runway. In effect, it is intended to keep the aircraft close to the OPD speed when it is far from the runway, but allow fine-tuning to achieve the spacing interval when close to the runway. It should be noted that figure 11 does not include some of the speed constraints in ASTAR, such as a function that limits the speed below 250 knots when the aircraft is below $10,000 \mathrm{ft}$.

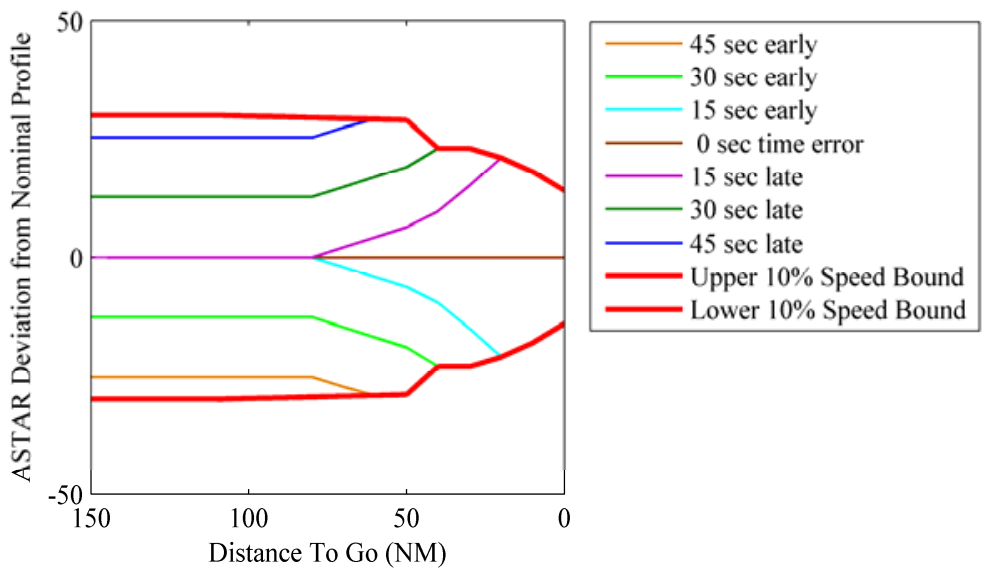

Figure 8. ASTAR Guidance.

\section{Results and Discussion}

This section of the paper describes the performance of the FIM operation, and the affect aircraft configuration and pilot conformance to operating procedures had on that performance.

\section{A. Performance of FIM Operation}

The primary goal of the ASTAR10 spacing algorithm is precise delivery of aircraft to the runway threshold at the assigned interval behind the two Target aircraft. Results from IMSPiDR indicate all aircraft assigned to both runways were able to arrive at the threshold within a mean of 2 seconds (4 seconds standard deviation) of the assigned spacing goals (Table 2).

Table 2. Runway Arrival Error for RTA+FIM.

\begin{tabular}{lcc}
\hline \hline Error Source & Mean (s) & SD (s) \\
\hline No Error & -1.81 & 3.87 \\
Wind Error & 0.90 & 3.91 \\
Offset Error & -2.16 & 3.29 \\
\hline
\end{tabular}

\section{B. FIM Operations During Optimized Descents}

The data presented in this section reflects the pre-conditioning of traffic during the IMSPiDR experiment to be within the requirements of the previous paragraph. More thorough analysis of the impact of time error as a function of distance to the runway will be accomplished by batch study. Figure 9 illustrates that some aircraft in the IMSPiDR experiment were required to change their speeds immediately after engaging the FIM equipment while other aircraft were able to fly for some distance before they needed to adjust their speed. Aircraft flew an average of 54 nautical miles before ASTAR10 adjusted their speed to achieve the assigned spacing. Some of the aircraft were able to fly 119 nautical miles before ASTAR10 adjusted their speed. This was a function of the initial conditions of the experiment, and will change based on the spacing error of the initial condition.

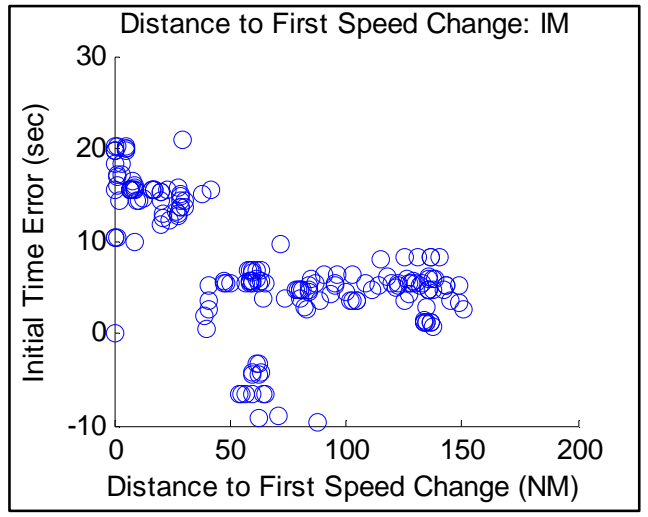

Figure 9. Distance before FIM Speed Change. 


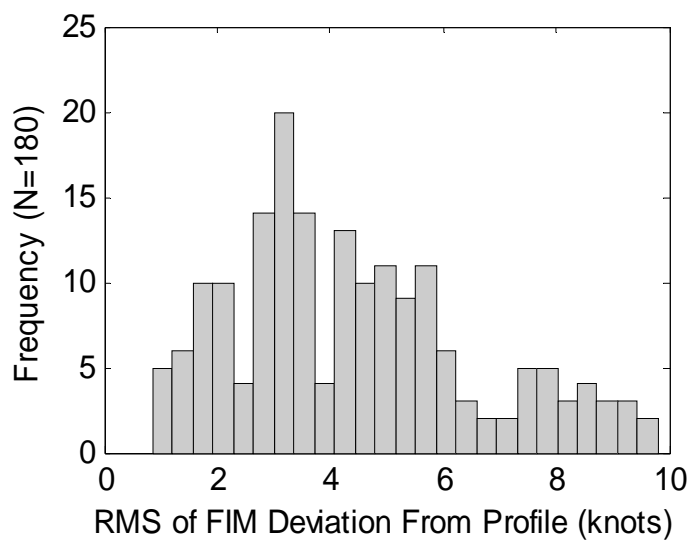

Figure 10. Difference between OPD speed and FIM speed.
One measure of how close ASTAR kept aircraft to their nominal OPD profile is the Root-Mean-Squared (RMS) difference between the FIM commanded speeds and the nominal OPD profile speeds (Figure 10). The RMS difference between the commanded speeds and the profile speeds was examined for differences between control methods and error sources. The results demonstrated that there were significant differences between error sources $(p<0.001)$, and significant interactions between the control methods and error sources $(p<0.001)$.

A Tukey pairwise comparison test was used to examine which factors were significantly different from each other, and revealed that the aircraft in the scenarios without error had the smallest deviation from the nominal profile, followed by the wind error and offset error scenarios. Additionally, there were a number of significant interactions between the errors sources and control methods. The most notable

interactions were between the RTA wind error scenarios and the RTA+FIM wind error scenarios. Table 3 shows that the aircraft that flew in the wind error scenarios using the RTA control method stayed significantly closer to their nominal profile than aircraft that flew in the wind error scenarios using the RTA+FIM control method. It is hypothesized that this occurred because RTA aircraft had to compensate for the wind error to achieve the scheduled time. In contrast, aircraft using the RTA+FIM control method were responsible for achieving an interval. Thus, when both the spacing aircraft and lead aircraft flew through the same wind error, the interval was maintained without the need for large corrections.

Table 3: Difference between the RTA and RTA+FIM speed.

\begin{tabular}{lcccc}
\hline \hline & \multicolumn{2}{c}{ RTA } & \multicolumn{2}{c}{ RTA+FIM } \\
\hline Error Source & $\begin{array}{c}\text { Mean } \\
\text { (knots) }\end{array}$ & $\begin{array}{c}\text { SD } \\
\text { (knots) }\end{array}$ & $\begin{array}{c}\text { Mean } \\
\text { (knots) }\end{array}$ & $\begin{array}{c}\text { SD } \\
\text { (knots) }\end{array}$ \\
\hline No Error & 2.8 & 1.7 & 2.2 & 1.3 \\
Wind Error & 6.0 & 2.0 & 3.6 & 1.2 \\
Offset Error & 5.0 & 1.8 & 4.9 & 2.2 \\
\hline \hline
\end{tabular}

One of the design goals for FIM operations is to enable aircraft to conduct OPDs during high-density operations. This data indicates that the ASTAR algorithm helped aircraft achieve a precise spacing interval, while allowing the aircraft to fly speeds that are close to the nominal OPD. The average deviation from the OPD was less than six knots for all experimental conditions, and no aircraft had an average deviation greater than ten knots (Table 3).

\section{Aircraft Configuration and FIM Performance}

\section{Speed Brakes}

Pilots in this experiment were instructed to fly the OPD profile programmed into the FMS, and to attempt to use the least amount of speed brake and flaps needed to maintain their speed within 5 knots of the FIM commanded speeds. A challenge of controlling aircraft speed when operating near minimum drag is that a small change in thrust or drag can create a relatively large change in airspeed (Figure 11). The OPD profile in the IMSPiDR experiment was designed so that aircraft flew at or near the Point of Neutral Stability (shown in blue). This made maintaining a particular airspeed challenging. To help pilots remain within \pm 5 knots of the FIM commanded speed, a "Drag Required” EICAS message was displayed when the aircraft's

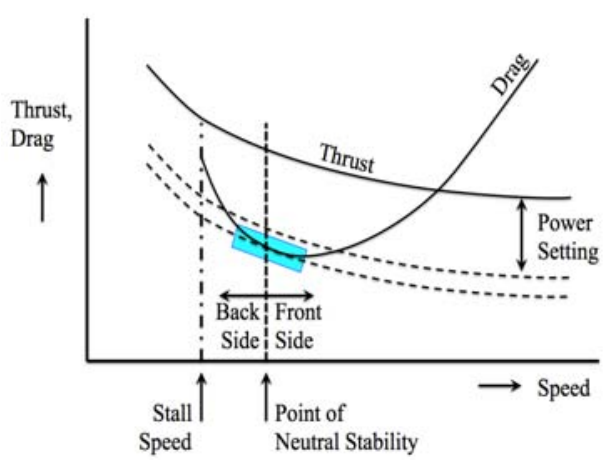

Figure 11. Region of OPD Operations. 
deviation from the FIM commanded speed was greater than six knots and suppressed when the aircraft was within four knots of the FIM commanded speed.

Figure 12 shows an arrival in which the pilot made extensive use of the speed brake to manage the aircraft's speed during the last 20 nautical miles of flight. This attentive use of speed brake and flap configuration to manage speed near the Point of Neutral Stability is important. Pilots have an understanding of this from current day operations, and in this experiment were typically able to effectively use speed brakes to control significant time errors created on final by wind shear and changing speed of the Target aircraft.

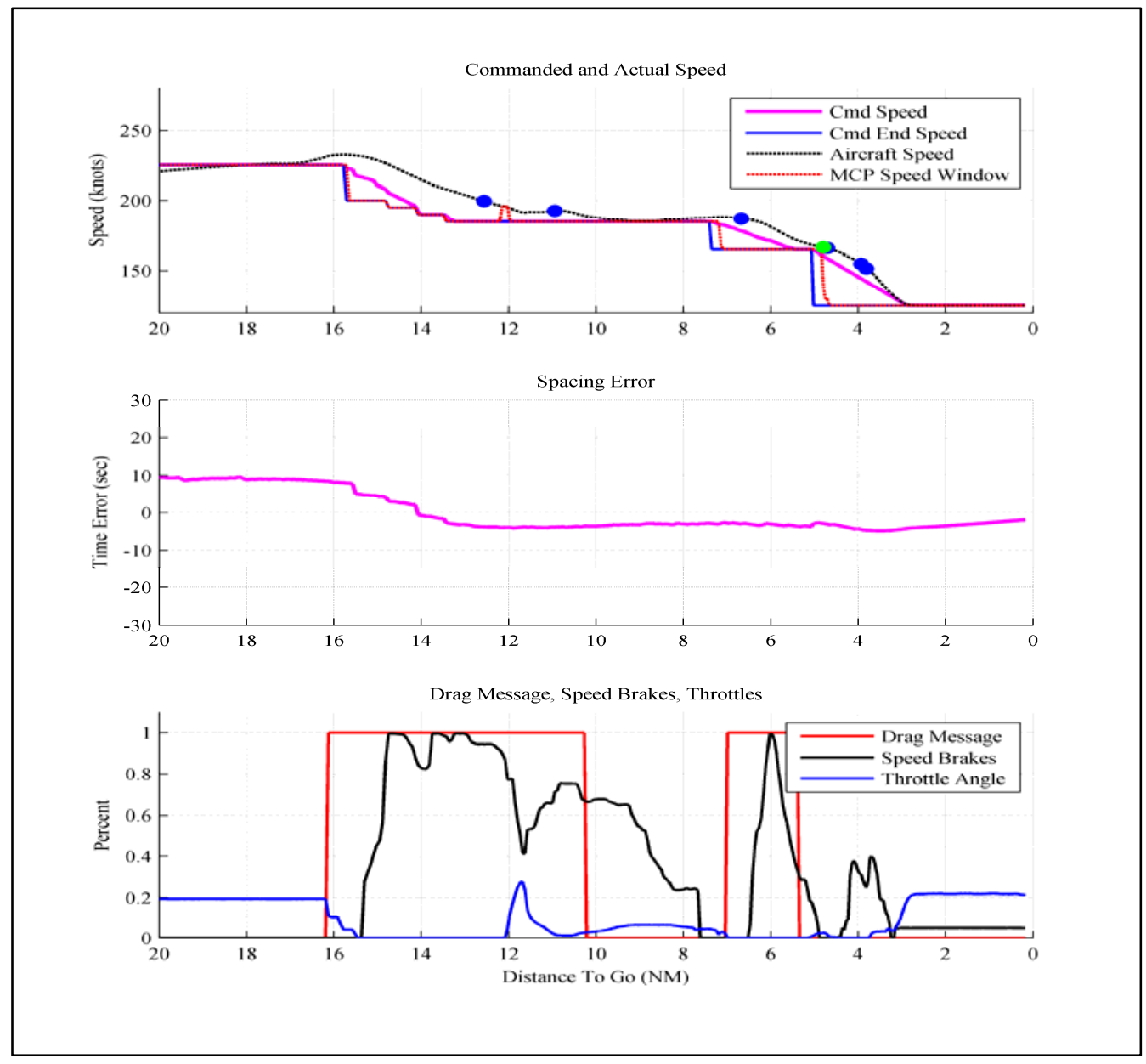

Figure 12. Airspeed, Spacing Error, and Speed Brake.

\section{Gear and Flaps}

In this experiment, the pilots' primary responsibility was to operate the aircraft safely and to use their normal procedures to ensure the aircraft's FIM commanded speeds were safe to fly. To reduce the amount of drag on the aircraft, pilots were instructed to use the minimum flap setting needed to achieve the FIM speeds calculated by ASTAR10. Pilots were also instructed to lower the landing gear, extend the flaps to 20 degrees, and set the aircraft's target speed in the MCP window when ASTAR commanded their FAS. After this point, pilots were required to configure the aircraft as necessary to be stable by 1000 feet AGL.

The data from this experiment showed all aircraft maintained appropriate flap settings for the aircraft's speed, and met all regulatory requirements (examples include at or below 250 knots when below 10,000 feet Mean Sea Level, and configuration and speed requirements for a stabilized approach). Some pilots used more than the minimum flap setting for their assigned speed, and some pilots lowered their landing gear well before they were required to. This data was analyzed to determine if there was a correlation between arrival time and distance from the runway when the pilot lowered the landing gear. 
The ASTAR10 spacing algorithm uses a nominal deceleration rate to predict the deceleration from the current arrival speed to the FAS. If the landing gear is lowered early, aircraft power can be increased to fly the FIM speeds, and the aircraft will slow to the FAS by reducing power. If the landing gear is lowered late (i.e., well after ASTAR10 commands the FAS), the interval error can increase since there is less drag on the aircraft than is predicted by the spacing algorithm.

The data illustrated in Figure 13 is a scatter plot of the gear deployed prior (early) or after (late) pilots were expected to deploy the gear, against arriving at the runway early (negative) or late (positive). Blue circles with positive time error show when the gear was lowered prior to ASTAR10 estimating it needed to be lowered and the aircraft arrived at the runway after the assigned spacing interval. Blue circles with negative time error show gear lowered early and a spacing interval at the runway less than assigned by ATC. Red circles with negative time error indicate gear lowered later than estimated and the spacing interval less than assigned by ATC, and red circles with positive time error indicate gear lowered late and the spacing interval larger than assigned by ATC.

Table 4 provides data for the mean and standard deviation from the assigned spacing interval for when the gear was deployed early (blue circles in Figure 13), and when deployed late (red circles in Figure 13).

It is noted that the relationship between the pilots lowering the gear and the FIM spacing interval error is a multi-faceted issue. Some pilots commented that they lowered the landing gear early to

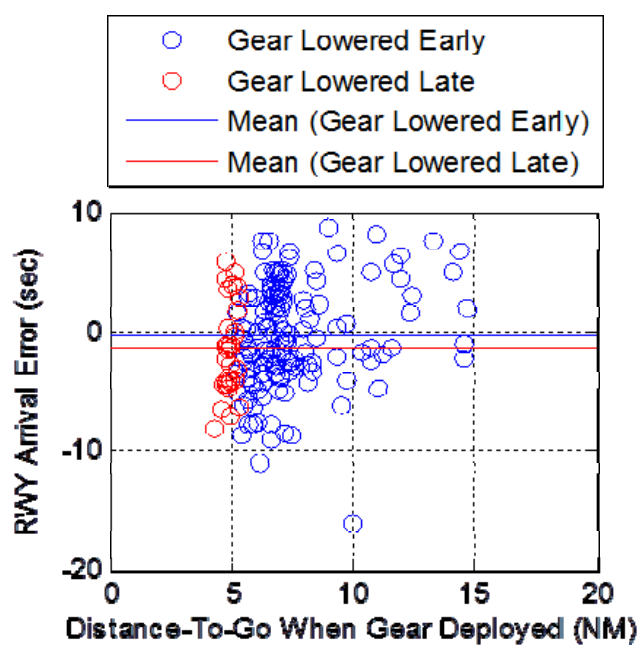

Figure 13. Time Error by Gear Deploy achieve the arrival speed ASTAR10 was commanding without using other forms of drag. Other pilots stated lowering the landing gear early allowed the use of higher power settings, which enabled more precise speed control, but at cost of additional fuel consumption.

Table 4. Interval Error by Early or Late Gear Extension

\begin{tabular}{lcc}
\hline \hline Gear Extension & Mean (s) & SD (s) \\
\hline Early & -0.30 & 4.43 \\
Late & -1.46 & 3.82 \\
\hline \hline
\end{tabular}

This cursory analysis does not appear to indicate an operationally significant difference between when the gear was deployed and the precision of the FIM operation. However, more detailed analysis is required before concluding that the ASTAR10 algorithm is robust to variance in pilots' execution of FIM procedures and the differences between the standard operating procedures of various airlines. Metrics required for this level of detail were not included in the IMSPiDR experiment, but will be in future research.

\section{Fuel Burn and FIM Guidance}

Fuel burn from $20 \mathrm{~nm}$ remaining was also evaluated to explore the impact of different techniques pilots used to configure the aircraft (primarily lowering the gear), while attempting to achieve the assigned spacing interval. Figure 14 shows the fuel burned during the final 20 nautical miles of flight. Aircraft that lowered their landing gear before ASTAR10 entered the FNL Mode are shown in blue, while those lowering the gear late are shown in red. The average fuel burn for each group is shown as horizontal lines.

Although all aircraft were able to arrive at the threshold within a mean of three seconds of the assigned spacing goal, this cursory analysis indicates the pilots who lowered their landing gear before ASTAR10 entered the FNL Mode did, on average, burn slightly more fuel to achieve their assigned spacing goal and most of the aircraft that lowered their landing gear beyond 10NM from

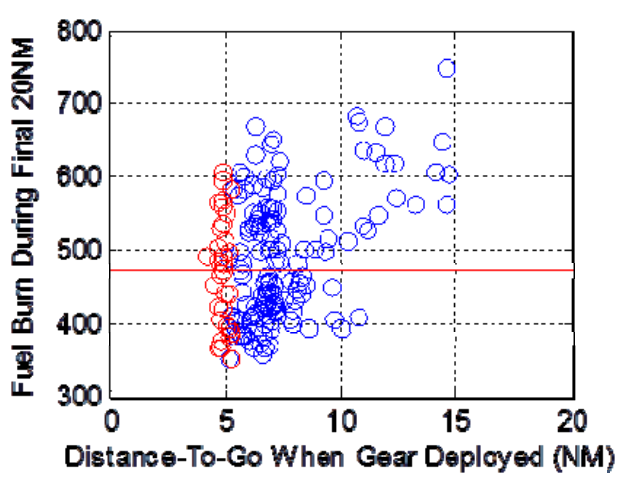

Figure 14. Fuel Burned vs. Gear 
touchdown had above average fuel burn. The difference in the average fuel burn for each group is less than 25 pounds. There are several things that can contribute to the narrow difference in average fuel burn. The vertical profiles flown were derived from charted arrivals into DFW and not optimized for the aerodynamic model of the aircraft used in this experiment. This analysis of fuel burn data for the last 20 nautical miles did not consider early deployment of flaps or deployment of speed brakes that were also used at this time to achieve the FIM clearance .

Future experiments need to be conducted with higher fidelity drag and engine performance data, and an understanding of the relationship between time delay required by FIM operations. In addition, research needs to be conducted to validate the amount of drag required to sufficiently control the aircraft speed when conducting FIM operations near the point of neutral stability for a given drag curve.

\section{Procedure Compliance and FIM Performance}

\section{Flight Crew Reaction Time to Speed changes}

While conducting FIM, it is important for pilots to respond to speed changes within an appropriate timeframe to ensure that the aircraft achieves its required spacing interval, and prevent ASTAR from commanding further deviations from the nominal profile. During this experiment, pilots in the IFD were expected to notice speed changes and dial them into the MCP speed window in a timely manner. Pilots in the ATOL and DTS had their auto-throttles coupled to the ASTAR commanded speed for a majority of the flight; however, the MCP speed window opened when they captured the ILS and the pilots were expected to manually dial the commanded speeds into the MCP speed window. The pilot's reaction time to these speed changes was defined as the time it took for pilots to dial the speeds into the MCP speed window after a new commanded speed is given.

The time it took pilots to notice and respond to commanded speeds (during both RTA and RTA+FIM operations) was examined and compared with assumptions made by the automation during the periods when the MCP speed window was open. To complete the analysis, the response time data was averaged for each run. If a new speed change occurred before the pilot reacted to the old speed change, the reaction time for that particular speed change was considered to be the time between the two speed changes. The square root of the response data was taken to transform it into a normal distribution to enable the use of non-parametric statistical analysis. The square root transformation provided a better, though not perfect, approximation of a normal distribution (Figure 18). When the square root of the reaction time was analyzed, significant differences were found between the error $(p=0.035)$ source and the simulator type $(p<0.001)$.
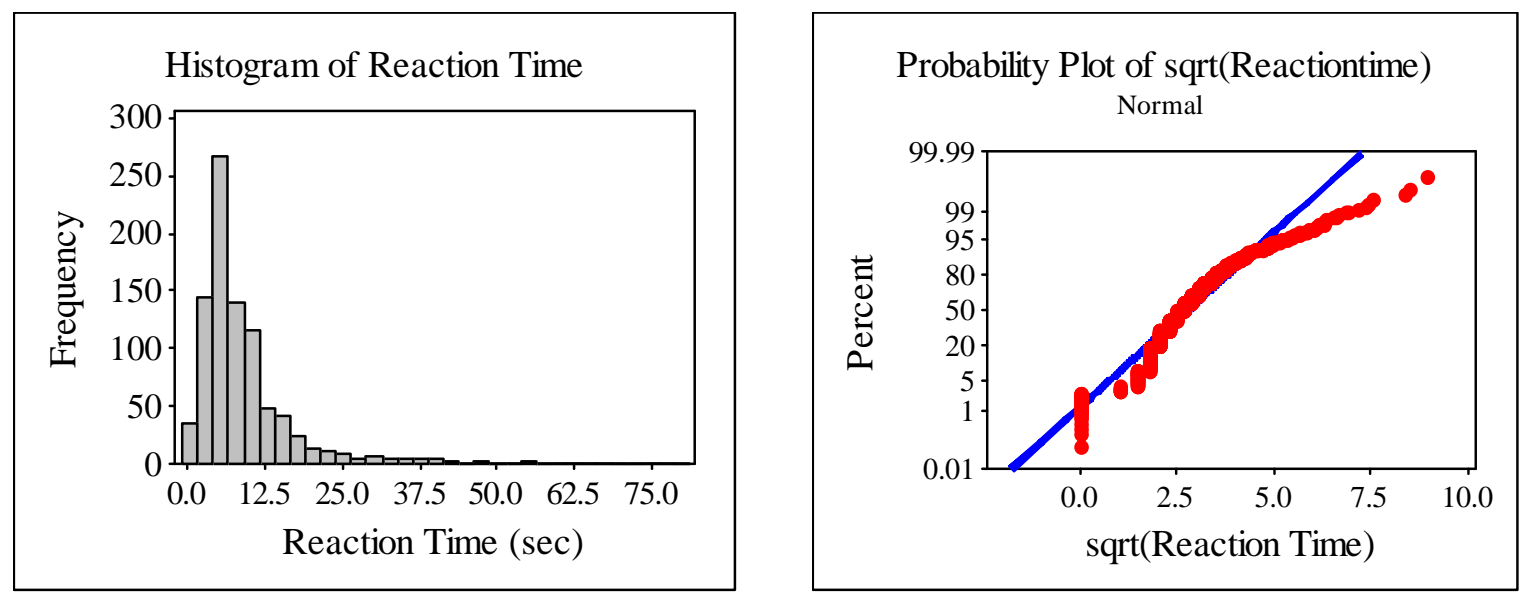

\section{Figure 15. Left to right, (a) Histogram of pilot reaction time to change in the commanded speed, (b)} Comparison of reaction time distribution to a normal distribution.

A Tukey pairwise comparison test revealed that the reaction times of the pilots in the scenarios without error were larger than the reaction times of the scenarios with wind error (Table 5). It is hypothesized that the scenarios without error had a larger reaction time because they had fewer speed changes, and the pilots may not have been looking for them as vigorously. 
There was also a statistically significant difference in the pilots' reaction time between the different simulator types, with the ATOL having the highest reaction time $(M=10.5, S D=9.2)$ and the IFD having the lowest reaction time $(M=6.6, S D=7.4)$. Part of the cause of the difference in reaction times between simulators may be that the IFD flew a majority of its arrival with the MCP speed window open, whereas the ATOL and DTS pilots had the commanded speed coupled directly to the auto-throttle, with the MCP speed window opening automatically when they captured the ILS. Pilots who flew in the ATOL and DTS commented that this transition often took them by surprise, since the FMS had managed their speed throughout a majority of the arrival.

Table 5: Pilot Reaction Time to FIM Speed Change by Condition

\begin{tabular}{lcccc}
\hline \hline & \multicolumn{2}{c}{ RTA } & \multicolumn{2}{c}{ RTA+FIM } \\
\hline Error Source & Mean (sec) & SD (sec) & Mean (sec) & SD (sec) \\
\hline No Error & 11.6 & 10.7 & 10.4 & 10.7 \\
Wind Error & 8.0 & 7.3 & 8.5 & 7.2 \\
Offset Error & 9.1 & 9.8 & 8.8 & 8.9 \\
\hline \hline
\end{tabular}

In addition to collecting data on the reaction time of pilots to speed changes, pilots were asked to provide the amount of time they thought would be reasonable to notice and implement a speed change. On average, pilot responses in the post experiment questionnaire indicated that they would consider noticing the speed change within nine seconds ( $S D=5, N=24$ ) of a commanded speed change, and dialing the speed commands into the MCP speed window within seven seconds $(M=7, S D=4, N=24)$ of noticing the speed command as acceptable.

The reaction time data shows that pilots were able to dial new commanded speeds into the MCP speed window within a reasonable period of time during all experimental conditions. However, it was determined that the reaction time was shorter for the scenarios with error conditions and for the simulator that required pilots to manually dial new commanded speeds into the MCP speed window throughout the entire arrival. Additionally, the reaction times observed in the experiment closely matched with reactions times pilots stated were reasonable in their postexperiment questionnaires. Furthermore, the reaction times for all conditions in this experiment were sufficient to enable the aircraft to achieve precise intervals behind their Target aircraft (Table 2).

\section{Flight Crew Compliance with Operating Procedures}

During the entire IMSPiDR experiment, there were 11 instances out of 180 data runs where the pilots did not properly comply with the FIM procedures. None of the errors impacted the safety of flight, constituted an operational error, or violated the FAR. Most of the errors were related to delays in implementing speed changes. Some procedural errors were additive and resulted in compounding the resultant interval achieved at the runway threshold. Other procedural errors canceled the effects of earlier procedural errors.

\section{Example of FIM Procedure Deviation using the Two Pilot IFD Simulator}

Figure 16 illustrates a data run where the pilots in the IFD did not properly follow the pilot procedures for following FIM commanded speed changes. The aircraft's airspeed stayed well above the Profile speed ("Cmd Speed"). A "Drag Required" EICAS message was displayed between $20 \mathrm{NM}$ and $5.5 \mathrm{NM}$, indicating to the pilots that their aircraft needed more drag to properly follow FIM guidance. Between 20 and 7.5 miles, the pilots failed to add sufficient drag to allow the aircraft to decelerate quickly enough to catch multiple speed reductions commanded by the ASTAR10 algorithm ("Cmd End Speed") between 20 and 16 miles. Sufficient drag was added when the landing gear was lowered at 7.5 miles from the threshold. Therefore, this lack of timely response and drag management caused a negative, or early, time error to build to approximately 28 seconds.

Another event occurred on this run that caused an interesting outcome. At approximately 7.5 miles remaining to the runway threshold, the ASTAR10 algorithm commanded a speed of 150 knots. The pilots lowered the landing gear, but instead of setting the FIM commanded speed of 150 knots in the MCP window, they set the FAS of 130 knots. This unexpected setting of the FAS caused the aircraft to decelerate well below the FIM speed guidance at that point on the approach, and as a result, substantially reduced the time error. The cumulative result of these multiple failures to follow FIM guidance was a spacing error of approximately 8 seconds.

This data indicates ASTAR10 will continue to update speed guidance to address the cumulative error of pilot deviation. The data also indicates that pilot training may need to be more extensive for some pilots, and FIM guidance and alerting may require adjustments to enable better adherence to FIM procedures. 


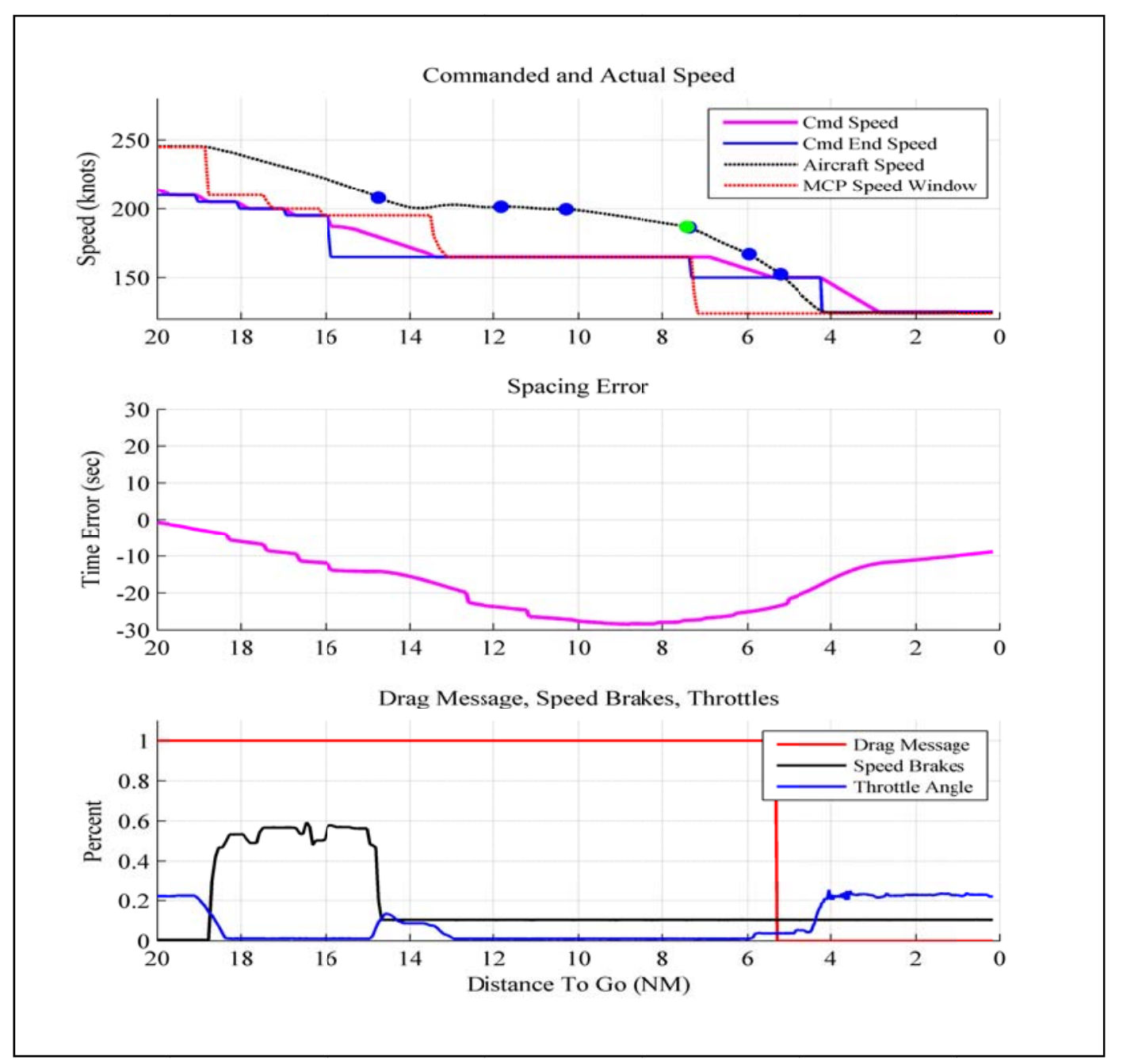

Figure 16. Failure to Follow FIM Guidance in the IFD.

\section{Example of FIM Procedure Deviation using the Single Pilot ASTOR Simulator}

Each of the ASTOR simulators were operated by a single pilot, consequently, those pilots did not benefit from having another pilot present to ensure FIM procedures were followed properly. Figure 17 is ASTAR10 data from and ASTOR during the final 10 miles of the approach, when the MCP speed window was open (after ILS capture) and the pilot was required to set the FIM commanded end speed manually in the MCP window. In the left panel, the pilot properly followed the FIM guidance as instructed. The ASTAR10 commanded end is shown in black, and corresponds to green speed at the top left of the PFD in Figure 5. The aircraft's commanded speed set manually by the ASTOR pilot in the MCP window is shown as a dashed magenta line in Figure 17. During this run, the pilot set the aircraft's commanded speed in the MCP window to match the FIM commanded end speed every time that speed changed.

The right panel of Figure 17 illustrates data from a single Required Time of Arrival (RTA) data run that had no induced
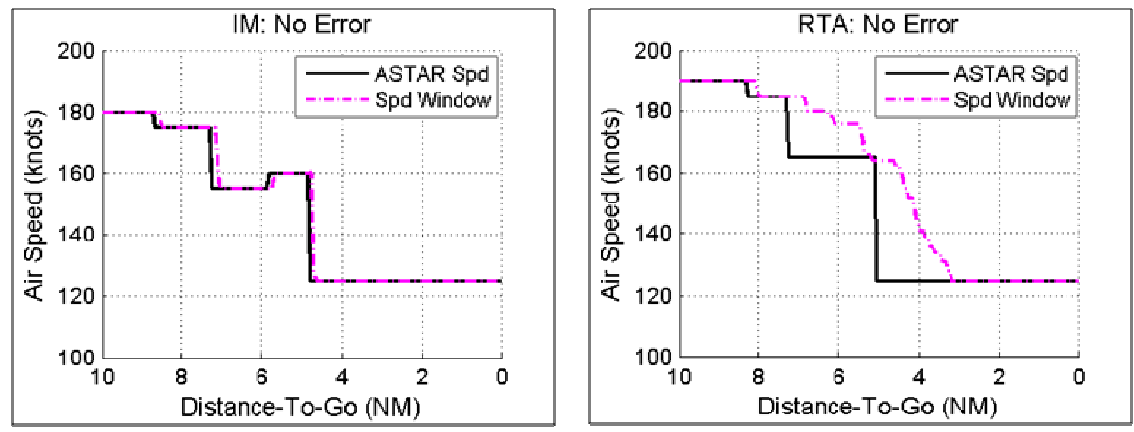

seed.
17

American Institute of Aeronautics and Astronautics 


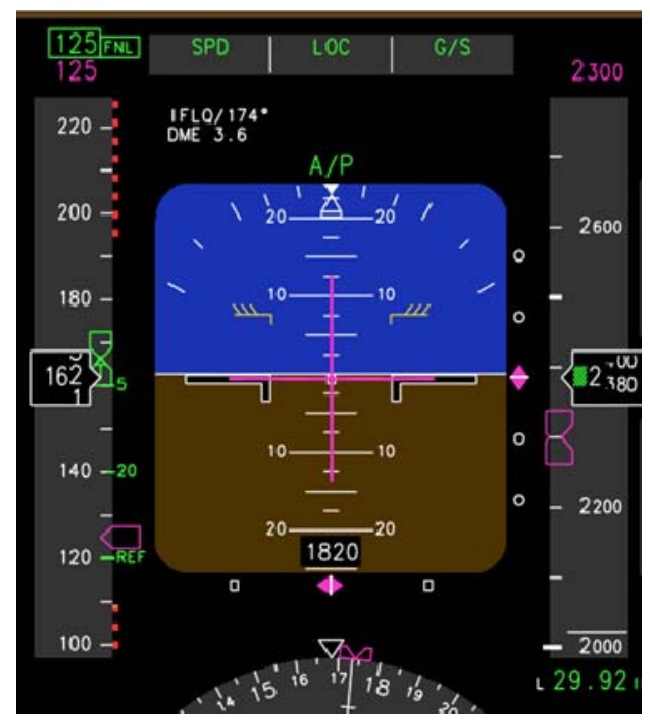

Figure 18. FIM Speed Guidance.

miles of flight when the aircraft was following ILS guidance, and manual speed entry of the FIM commanded speed generated speed was required. In this example, instead of correctly entering the FIM commanded end speed (green number in upper left of PFD, Figure 18) into the MCP window, the pilot continuously adjusted the MCP speed to match the FIM commanded speed (green speed bug to right of the speed tape). This speed was intended to be available to the crew to provide an estimate of the deceleration rate, and is not appropriate to act as a guide for the speed to set in the MCP.

This unexpected behavior of the pilot did not substantially affect the precision performance of the experiment shown in Table 2. This is due in part to the robustness of the algorithm, which is continuously calculating a corrected speed for the pilots to fly. In setting the MCP speed to the speed indicated by the FIM speed bug at the edge of the speed tape, the pilot was required to spend a substantial amount of time tracking the speed bug and setting the aircraft's commanded speed in the MCP speed window to match the FIM commanded speed. The pilot did not identify his method of complying with the ATC FIM clearances in his post flight questionnaires.

\section{Conclusions}

This paper examined aircraft configuration and flight crew compliance with procedures while conducting FIM operations to parallel dependent runways. All aircraft were able to arrive at the threshold within a mean of 2.2 seconds (4 seconds standard deviation) of the assigned spacing goals. Further analysis indicates that aircraft that lowered their landing gear earlier than expected by the ASTAR10 algorithm burned on average slightly more fuel to achieve their assigned spacing goal than aircraft that did not. This suggests that, in some cases, the way the pilots configured the aircraft affected the amount of fuel the aircraft burned to achieve the desired spacing. The results also indicate configuring the aircraft's flaps and gear early had little effect on the spacing error. Future research needs to be conducted to validate the amount of drag required to sufficiently control the aircraft speed when conducting FIM operations near the point of neutral stability for a given drag curve, and the fuel penalty it incurs.

This experiment also showed that OPD arrivals can be conducted in conjunction with FIM operations. FIM is designed to keep the aircraft close to the nominal profile while achieving a precise interval behind a Target aircraft. Aircraft were commanded less than 10 knots average deviation from the nominal profile, despite scenarios with large wind errors and perturbations. Supporting results from previous research, the difference between profile and FIM speed during RTA scenarios was significantly higher than RTA+IM scenarios when in the presence of wind error. This suggests that relative spacing is more robust and requires less correction than a time only control method when wind errors are present. Furthermore, with the initial conditions in the experiment, some aircraft were able to fly a substantial distance before needing to deviate from their nominal speed profile to achieve their assigned spacing interval.

Analysis was conducted on how pilots configured the aircraft, and how they followed the FIM speed guidance. The assumption had been that that the pilots would fly the speeds provided by FIM avionics within the specified tolerances. Most pilots were able to notice speed changes and ensure that the aircraft was achieving the commanded speeds; however, there were instances where pilots did not comply with the commanded speeds and other operational procedures. When this occurred, if sufficient time remained, the ASTAR10 algorithm was able to calculate new FIM speeds to compensate for the accumulating time error. One unexpected issue in particular was observed when a pilot used the incorrect form of the FIM speed. The discreet FIM commanded end speed was to be used by the pilots when setting the MCP speed. The continuously updated speed displayed as a speed bug at the edge of the speed tape was to allow the pilots to determine if the actual deceleration rate was slower or faster than the deceleration rate predicted by the ASTAR10 algorithm. In a couple cases, the pilot set the MCP speed to follow the speed bug at the edge of the speed tape instead of setting it to the FIM commanded end speed. 


\section{References}

1 “FAA Aerospace Forecast, Fiscal Years 2011-2031,” U.S. Department of Transportation Federal Aviation Administration Aviation Policy and Plans, Washington, DC, 2010.

${ }^{2}$ Federal Aviation Administration, “Arrival Interval Management - Spacing (IM-S) Concept of Operations for the Mid-Term Timeframe”, FAA ATO-E, Version 1.5.3, Coordination Draft, Oct 2011.

${ }^{3}$ Murdoch, J., Barmore, B., Baxley, B., Abbott, T., and Capron, W., "Evaluation of an Airborne Spacing Concept to Support Continuous Descent Arrival Operations," 8th USA/Europe Air Traffic Management Research and Development Seminar (ATM2009), Napa, CA, June 2009.

${ }^{4}$ Barmore, B., Abbott, T., Capron, W., and Baxley, B., "Simulation Results for Airborne Precision Spacing along Continuous Descent Arrivals," 26th Congress of the International Council of the Aeronautical Sciences (ICAS2008) including the 8th AIAA Aviation Technology, Integration, and Operations Conference (ATIO), paper ICAS 2008-11.9.2 / AIAA 2008-8931, Anchorage, AK, Sept. 2008.

5 "Safety, Performance and Interoperability Requirements Document for Airborne Spacing-Flight Deck Interval Management (ASPA-FIM),” RTCA DO-328, RTCA, Washington, DC, June 2011.

${ }^{6}$ Barmore, B., Baxley, B., Abbott, T., Capron, W., Smith, C., Shay, R., and Hubbs, C., “A Concept for Airborne Precision Spacing for Dependent Parallel Approaches”, NASA-TM 2012-217346, NASA Langley Research Center, VA.

7 Abbott, T., "An Overview of a Trajectory-Based Solution for En Route and Terminal Area Self-Spacing to Include Parallel Runway Operations,” NASA/CR-2011-217194, NASA Langley Research Center, Hampton, VA, Nov. 2011.

${ }^{8}$ Swieringa, K., Murdoch, J., Baxley, B., and Hubbs, C., "Evaluation of an Airborne Spacing Concept, On-board Spacing Tool, and Pilot Interface”, 11th AIAA Aviation Technology, Integration, and Operations Conference (ATIO), AIAA 2011-6902, Virginia Beach, VA, Sept. 2011.

9 Baxley, B., Hubbs, C., Shay, R., and Karanian, J., "Use of Data Comm by Flight Crew to Conduct Interval Management Operations to Parallel Dependent Runways”, 11th AIAA Aviation Technology, Integration, and Operations Conference (ATIO), AIAA 2011-6972, Virginia Beach, VA, Sept. 2011.

${ }^{10}$ Baxley, B., Swieringa, K., and Capron, W., "Interval Management with Spacing to Parallel Dependent Runways (IMSPiDR) Experiment and Results," 28 $8^{\text {th }}$ International Congress of the Aeronautical Sciences (ICAS2012)” ICAS2012-9.10.3, Brisbane, Australia, Sept. 2012.

11 "Flight deck-based Interval Management (FIM) Controller Pilot Data Link Communications (CPDLC) Messages,” draft v1.0, RTCA SC-214 / EUROCAE WG-78 and RTCA SC-186 / EUROCAE WG-51 Tiger Team, Washington DC., July 15, 2011.

12 “Global Operational Data Link Document (GOLD),” $1^{\text {st }}$ Edition, International Civil Aviation Organization (ICAO), June 14, 2010 